\title{
Bridging Literacy Acquisition and Self-regulated Learning: Using a SRL Framework to Support Struggling Readers
}

\author{
Sierra Holtzheuser \& John McNamara \\ Brock University
}

\begin{abstract}
Reading is conceptualized as a hierarchy of component skills where lower order emergent literacy skills set the foundation for higher order reading skills such as fluency and comprehension. Approximately $20 \%$ of readers struggle within this hierarchical process (Fielding, Kerr, \& Rosier, 2007). Struggling readers are susceptible to the Matthew Effect, a reading trajectory that sees them fall further behind their grade-level reading peers as they progress through their school grades. The purpose of this paper is to present a model of reading that considers self-regulated learning as an important motivational factor, particularly for children at-risk for reading difficulties. We describe reading acquisition within the context of task understanding and perceived self-efficacy, goal setting, strategies and tactics, and monitoring and feedback-the self-regulated learning process (see Winne \& Hadwin, 1998).
\end{abstract}

Over the past three decades, research in the field of reading difficulties has clearly elucidated the predictive relationship between a number of component skills and proficient reading (Adams, 1990; Phillips, Clancy-Menchetti, \& Lonigan, 2008). Such component skills include print awareness, letter-sound understanding, phonemic awareness, expressive and receptive vocabulary, and fluency (Snow, Burns, \& Griffin, 1998). However, the field is less informed about contextual variables associated with effective reading. The focus on contextual factors is particularly important given that struggling readers are vulnerable to the Matthew Effect, whereby strong readers continue to get stronger and poor readers continue to get poorer (Stanovich, 1986). The Matthew Effect may be the result of a lack of motivation on the part of struggling readers. Stanovich (1986) referred to the Matthew Effect as a prevalent phenomenon for vulnerable readers and posited that children who demonstrate early reading difficulties are slower in their basic reading acquisition. As a result, they experience less exposure to vocabulary and have fewer opportunities to engage in reading practice. As such, these children experience a decrease in motivation to engage with reading-based material, compounding the effects of their initial reading delay. Therefore, it becomes important to focus not only on how to teach effective 
component reading skills, but also how to promote motivation tactics and strategies for those with reading difficulties.

A number of researchers have studied the importance of self-regulated learning (SRL; e.g., Azevedo, 2009; Butler, 1998; Butler \& Winne, 1995; Winne, 2010; Zimmerman, 2008), some of which have begun to elucidate the importance of bridging reading instruction within models of SRL (Butler, 1998). However, researchers are still working toward practical instructional models that effectively integrate SRL and reading. We attempt to contribute to the literature by combining our conceptualization of reading acquisition with a model of SRL proposed by Winne and Hadwin (1998), to describe specific methods of reading instruction to support struggling readers. The purpose of this paper is to explore how to support struggling readers as they move through the proposed reading hierarchy by adopting an instructional regime couched in a model of SRL.

\section{Components of Reading}

Before considering how SRL can be understood as an important contextual variable within the reading acquisition process, it is important to operationally define the model of reading we propose in this paper. First, we refer to reading acquisition as a complex process that includes the development of a number of skills (Stuart, Stainthorp, \& Snowling, 2008). Since the seminal work of Adams (1990), numerous models have conceptualized reading. Such models vary in a number of ways; perhaps most salient is the debate over whether reading should be conceptualized as stage-based or non-staged-based (Beech, 2005; Ehri, 1992; Spear-Swerling \& Sternberg, 1996; Stuart et al., 2008). Proponents of the stage-based model suggest that readers' progress through various reading skills and stages independently of one another in a linear fashion (Beech, 2005; Stuart \& Coltheart, 1988). More specifically, it is not until a child has mastered previous reading skills that they should move to the next discrete stage. Popular stage-based theorists include Ehri (1992; 2005), Frith (1985), and Seymour (1986; see Stuart \& Coltheart, 1988, for a review of theories). Alternatives to stage-based models include conceptualizations of reading as non-stage-based, whereby reading is a continuously developing phenomenon with various components developing concurrently (Stuart et al., 2008). In these models, reading development does not occur in a linear fashion, nor do children have to progress through a sequence of stages to become skilled readers. Proponents of this perspective posit that children may demonstrate differential ability in word recognition and language comprehension processes (Stuart et al., 2008). In this paper, we have considered each of the above perspectives and combined elements of both stage- and non-stage-based theories. While we do not necessarily believe that reading acquisition occurs in a linear fashion, we do believe that some skills are foundational for others to develop. As such, we propose a model of reading as a hierarchy of skills whereby higher order reading skills are built upon lower order skills (see Figure 1).

Lower order skills may be characterized by those more primary literacy skills learned as isolated skills sets (i.e., letter-sound understanding), whereas higher order skills (e.g., reading fluency and comprehension) are dependent upon the development and interactive operation of lower order skills. For example, the ability to derive meaning from a text involves background knowledge of concepts, pronunciation, verbal reasoning abilities, and letter-sound understanding (McCardle, Scarborough, \& Catts, 2001). However, it is also important to acknowledge that each skill does not develop independently of one another. For instance, letter-sound understanding and phonemic awareness (the ability to hear, identify, and manipulate phonemes) co-developparticularly in the early stages of reading. A second caveat to the hierarchy presented in this paper is that many of the skills may be considered pre-reading or emergent literacy skills. 


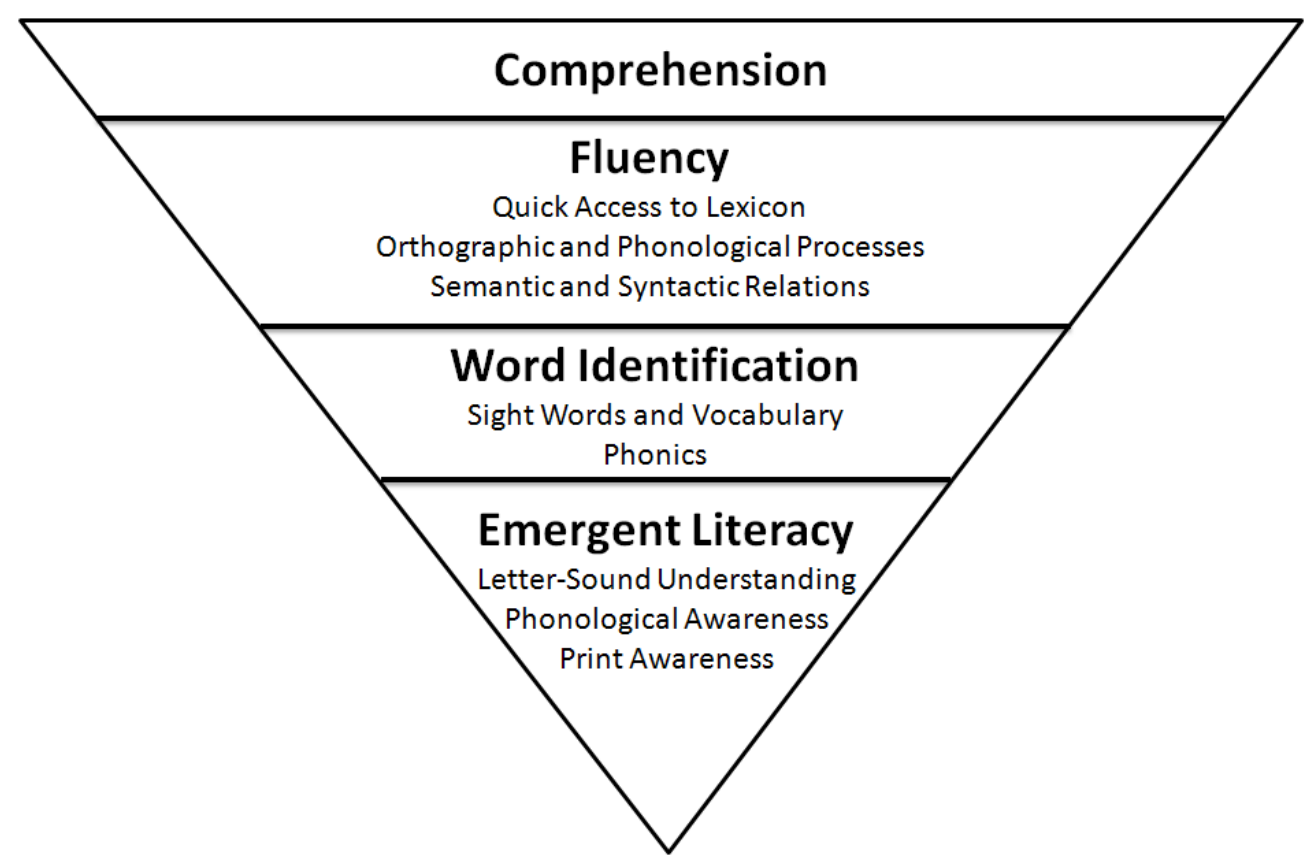

Figure 1. Reading Hierarchy.

\section{Emergent Literacy}

Teale and Sulzby (1986) proposed the term "emergent literacy" to define the developmental period from birth through age 6 when children are "in the process of becoming literate" (p. xix). They argued that during this phase, children are developing, learning, and acquiring necessary skills in written language, even prior to being exposed to formal schooling. In the model presented here, emergent literacy skills are those that are most primary and include print awareness, letter-sound understanding, and phonological awareness.

Print awareness may be conceptualized as a child's emerging ability to understand the form and function of written language (Justice \& Ezell, 2001). This includes understanding the left-toright and top-to-bottom directionality of print, as well as understanding and recognizing letters, words, and symbols as they appear in written language. Print awareness is a foundational skill that gradually develops in the preschool years and is an excellent predictor of later reading achievement (Justice \& Ezell, 2001; Stuart, 1995).

Developing concurrently with print awareness is letter-sound understanding. Letter-sound understanding refers to a child's ability to recognize the graphic symbols, the name, and the sound(s) associated with each letter (Foulin, 2005). The ability to associate letter names with lowercase and uppercase graphemes is referred to as letter recognition and is a strong predictor of success in early reading achievement (Catts, Fey, Zhang, \& Tomblin, 2001; Foulin, 2005; Scarborough, 1998). Letter recognition is crucial in developing the ability to associate letters and groups of letters with the sound(s) they make. Research elucidates the predictive ability of early letter-name recognition and letter-sound understanding on later spelling abilities (Pennington \& Lefly, 2001) and enduring reading achievement throughout elementary school (Caravolas, Hulme, \& Snowling, 2001; Hecht, Burgess, Torgesen, Wagner, \& Rashotte, 2000).

The final skill within emergent literacy is phonological awareness or the ability to focus on and manipulate sounds in spoken language (Castles \& Coltheart, 2004; National Reading Panel, 
2000). Phonological awareness is comprised of various skills beginning with basic speech unit sounds - phonemes - as well as larger units, such as oral rhyming and alliteration, and working toward the ability to manipulate sounds in words through blending and segmenting (see Castles \& Coltheart, 2004, for a review of phonological awareness). Research has indicated that phonological awareness is significantly predictive of later reading and furthermore, it has been suggested that phonological processing problems are at the core of most children's reading difficulties (Phillips et al., 2008). Having a strong phonological awareness prepares children for reading instruction, including phonics, spelling, and word identification (Adams, Foorman, Lundberg, \& Beeler, 1998; National Reading Panel, 2000).

\section{Word Identification}

Word identification, or word-level reading, is the next step in the proposed reading hierarchy. However, it is important to realize that children who demonstrate difficulties with emergent literacy skills are at a significant disadvantage when faced with decoding whole words (Snow et al., 1998). Word identification refers to one's ability to decode unfamiliar words and recognize familiar words through phonics and vocabulary instructional strategies (Snow et al., 1998). It is not within the scope of this paper to review the abundance of word identification instructional strategies, tactics, and programs that exist but simply to recognize that strong word identification provides the basis for fluent and comprehensive reading (Ehri, 1992).

One basic instructional strategy deserving mention within the proposed hierarchy is phonics. Phonics is a method of reading instruction that has an explicit focus on the associations between letters and sounds in written language (Phillips et al., 2008), as well as how to apply this knowledge to reading and spelling (National Reading Panel, 2000). Phonics instruction builds upon letter-sound understanding, as it directly and explicitly teaches letter-sound patterns, onsets and rimes, as well as blending and segmenting in print. This form of instruction helps children understand that there are predictable and systematic relationships between spoken sounds (phonemes) and written letters (graphemes), which is an important aspect of decoding (Stuart et al., 2008). Research suggests that direct and systematic phonics instruction improves children's word recognition, spelling, and comprehension (National Reading Panel, 2000; Snow et al., 1998).

While teaching phonics is important for decoding new words, many words in the English language are irregular and do not follow phonetic principles. Therefore, children must also develop a vocabulary of sight words. Sight words are high-frequency, often irregular words that children recognize instantly and automatically (Fleming, 2006). There are many common lists of sight words currently in use, including the Dolch list and the Fry list. These sight words make up $60-70 \%$ of text in children's early reading materials (Fleming, 2006). A child who has a large sight word vocabulary can therefore recognize the majority of words in a typical selection, allowing the child to focus on the content rather than on the process of reading. For that reason, research suggests that children with a large oral and reading vocabulary are not only more fluent readers, but are better able to comprehend what they are reading compared to children who disrupt the comprehension process to decode, analogize, or predict individual words (Ehri, 2005).

\section{Fluency}

Fluency is the ability to read aloud or silently, in a quick, accurate manner with proper expression (National Reading Panel, 2000), and is strongly associated with reading ability and reading comprehension (Fuchs, Fuchs, Hosp, \& Jenkins, 2001). Reading fluency involves the development of various components that operate concurrently to result in skilled reading (Ad- 
ams, 1990; Fuchs et al., 2001). These components include rapid access of the lexicon, phonological and orthographic processes, and syntactic and semantic relations (Adams, 1990). The speed of lexical retrieval, sometimes referred to as rapid naming, is considered an important aspect of fluency. Quick access to lexicon is indicative of how readily children can gain access to a sound, a sound-sequence, or a word meaning (Bowers \& Swanson, 1991; Cornwall, 1992). The lexical processing of a word involves access to the word's representation in orthographic input lexicon, and the retrieval of the word's spoken form from the phonological output lexicon (Verhoeven \& Perfetti, 2011). Orthography refers to spelling in conventional usage, including phonological and non-phonological aspects of spelling (Treiman \& Kessler, 2004). Phonological processes refer to skills that involve the use of the sound structure of oral language in learning to read (Cornwall, 1992; Torgesen, Wagner, \& Rashotte, 1994). This combination of orthographic and phonological processes is important, as many words have the same sequence of letters but are pronounced differently (e.g., "ough" has six different sounds in English). It has been noted that using orthographic knowledge in phonological tasks — or knowledge of a word's spelling to make judgments about the sounds in a word-is evident in normal readers but less so in struggling readers (Landerl, Frith, \& Wimmer, 1996). Finally, fluent reading involves syntactic awareness about how sentences are worded and structured (Adams, 1990). In general, fluency is a complex, multi-component skill that requires the integration of several cognitive processes.

\section{Reading Comprehension}

The ultimate goal of reading is to comprehend written language (Cartwright, 2008). Reading comprehension is the ability to derive information from text and involves evaluating context clues to assign the correct meaning to each word. The automatization of word recognition and fluent reading are both essential for comprehension (Perfetti, 1992; Verhoeven \& Perfetti, 2011). According to the National Reading Panel (2000), research on the development of reading comprehension includes three main themes. First, vocabulary development and instruction play a key role in understanding a text. The larger a child's oral and reading vocabulary, the easier it is to understand a given text. Second, reading comprehension is an active process whereby a reader must intentionally and thoughtfully interact with the text, for example predicting the outcome of the story based on the story's title. Finally, teachers must be prepared to develop and apply reading comprehension strategies, and their preparedness is intimately linked to student achievement. Many factors influence reading comprehension including, but not limited to, motivation, background knowledge, and cognitive variables (Taboada, Tonks, Wigfield, \& Guthrie, 2009); however, addressing each of these factors is not within the scope of this paper. As the abovementioned component skills develop, so does one's ability to comprehend written text. Most importantly, once one has developed through the hierarchy and has become a skilled reader, he or she can then use reading as a tool for further learning.

\section{The Matthew Effect}

Considering the proposed hierarchy described above, it is reasonable to assume that children will move through the hierarchical reading acquisition process at different rates and with different inherent and acquired skill levels. The factors affecting children's developmental trajectories through the reading hierarchy include environmental factors, such as familial influence, socioeconomic status, quality of education, and culture, as well as inherent traits such as phonological processing difficulties or cognitive capabilities (i.e., intelligence; Case, Speece, \& Molloy, 2003; Crosnoe, Leventhal, Wirth, Pierce, \& Pianta, 2010; Morris et al., 2012). 
An important contextual factor discussed in this paper is motivation. Motivation and reading hold an important reciprocal relationship, perhaps captured best by the idea of the Matthew Effect proposed by Stanovich (1986). This effect posits that children who demonstrate early difficulties in phonological awareness are slower in their word-level decoding and as a result experience less exposure to reading vocabulary and have fewer opportunities to engage in reading practice. In essence, reading delays interact with motivational factors to produce conditions whereby children with poor phonological awareness begin their trajectory throughout formal schooling at a significant disadvantage compared to their peers. Subsequently, as these children progress through their primary schools years, the gap in reading achievement scores between themselves and their grade-level reading peers increases exponentially, thus leading to a situation where struggling readers continue to fall further behind. This leads to a cycle of academic failure and frustration that is difficult to remediate. Another important aspect of the Matthew Effect related to children with reading difficulties is what Stanovich (1986) described as fan-spread effects. Fan-spread effects occur when children's problems that are initially specific to the area of phonological awareness fan out to become more generalized to areas of word-level reading and eventually, reading fluency and comprehension. This often materializes in children who had specific reading difficulties now experiencing general academic failure and frustration.

Following Stanovich's work with the Matthew Effect, researchers and educators have focused on how best to support children to decrease or eliminate the effects of poor reading achievement, decreasing the gap between strong and poor readers. A great deal of this research has focused on early identification and support of reading difficulties as researchers (e.g., Snow et al., 1998) pointed to the importance of early intervention for children at-risk for reading difficulties in counteracting the Matthew Effect. Following this, research has focused almost exclusively on how to establish early, effective screening, assessments, and interventions for young vulnerable readers (see McNamara, Scissions, \& Gutknecth, 2011). It has been argued that early identification of those at-risk for reading difficulties would enable professionals to limit the development of these problems (Lyon et al., 2001; Torgesen, Wagner, Rashotte, Burgess, \& Hecht, 1997). Remedial reading programs often include explicit direct instruction in the lower order reading skills described in the hierarchy presented in this paper, and the list of published programs is impressive. However, sustainability of achievement gains associated with such published reading programs has been called into question. O'Connor, Notari-Syverson, and Vadasy (1996) argued that brief literacy interventions (less than 15 weeks) are generally insufficient to produce achievement gains that are sustained beyond the short-term. Therefore, it is important to explore contextual factors that may enhance the achievement gains and sustainability of reading programs. A few research studies have begun to study such factors. For instance, Graham, McNamara, and Van Lankveld (2011) examined the impact that including caregivers as an integral component to literacy programs can have on long-term achievement gains. This paper attempts to add to the field's understanding around contextual variables and reading by exploring how the instructional reading process can be couched within a model of SRL.

\section{Self-Regulated Learning}

Self-regulation refers to self-created thoughts, behaviours, and feelings that are devised and cyclically adjusted to the achievement of personal goals and is contingent upon self-beliefs and affective feedback (Zimmerman \& Schunk, 1989). Self-regulation is considered a cyclical process as the feedback from previous performances is used to make modifications during current performances. Therefore, SRL-a complex process that develops over time-is the self- 
directive, interactive process whereby learners target their own cognitions, actions, emotions, and aspects of the environment for academic achievement (Ainley \& Patrick, 2006; Azevedo, 2009; Azevedo \& Witherspoon, 2009; Lodewyk, Winne, \& Jamieson-Noel, 2009). In more practical terms, SRL may be viewed as a style of engaging with tasks whereby students employ a set of skills that enhance their learning experience (Butler \& Winne, 1995; Winne \& Hadwin, 1998). Specifically, models of self-regulation propose that learning is effective when students understand their task, set goals for themselves, are deliberate about strategies and tactics they need to employ during a task, and monitor the effects of their engagement (Butler \& Winne, 1995).

Over the past two decades, a great deal of research has explored the positive effects on learning that results when students self-regulate effectively (Butler, 1998; Butler \& Winne, 1995). An important feature of this research is that learning and student engagement are intrinsically connected. That is, cognitive engagement and learner motivation should be considered as an inter-connected process whereby the products of cognitive engagement directly affect learner's self-efficacy thus impacting motivation processes for future tasks (Butler, 1998; Corno, 1993). The purpose of this paper to explore how to best support vulnerable readers as they move through the proposed reading hierarchy by adopting an instructional approach that is couched within the model of SRL proposed by Winne and Hadwin (1998).

\section{Reading and Self-Regulated Learning}

As discussed previously, vulnerable readers are susceptible to the Matthew Effect-a reading trajectory that sees them fall further behind their grade-level reading peers as they progress through their school grades (Stanovich, 1986). Proposed here is the notion that one explanation for this trajectory is that poor readers lack the SRL skills that may otherwise enable a motivational process in strong readers. Following this, it is important that educators and stakeholders concerned with supporting struggling readers consider how reading instruction can be couched within a model of SRL. Not only will this type of instructional regime support the academic skills needed to read, but it will also engage motivational processes that will support long-term reading success.

The following section describes how the reading acquisition process can be considered within four SRL constructs proposed by Winne and Hadwin (1998). Specifically, we describe the reading acquisition process within the context of task understanding and perceived self-efficacy; goal setting; strategies and tactics; and monitoring and feedback.

\section{Task Understanding and Perceived Self-Efficacy}

Understanding the demands of a task is an important first step in the self-regulatory learning process, as it sets the foundation for how a learner will engage. Winne (2010) described this as a process whereby learners come to cognitive activities with preconceived perceptions about the task and their own expectations for success or self-efficacy - a learner's understanding and beliefs regarding his or her ability to perform certain goal-oriented tasks (Bandura, 1997; Winne, 2010). Following this, struggling readers may come to reading activities with perceptions that intercede how they will engage with reading. For instance, struggling readers may have encountered previously unsuccessful reading experiences that have led to internalizing a lower sense of self-efficacy and thus decreased motivation. Under these circumstances, it would be reasonable to expect that the same reader would approach subsequent reading tasks with perceptions about the task that may mediate negative engagement. 
Task understanding is thought to be influenced by two primary processes (Venkatesh \& Shaikh, 2011; Winne \& Hadwin, 2008). First, task understanding is influenced by a learner's perceptions of the nature and demands of the task as well as how the outcomes will be evaluated. Winne and Hadwin (2008) found that a common difficulty within the self-regulatory learning process is that a learner's task understanding does not accurately reflect the actual demands of the target exercise. The second process involves learners' knowledge of themselves as learners within the context of the task. This may be particularly problematic for children with reading difficulties as their task-specific self-efficacy may be particularly low, most likely a result of the Matthew Effect.

The above-mentioned task understanding process intricately relates to learners' perceived self-efficacy. That is, many struggling readers may resist reading-based tasks, thinking that they lack the ability to succeed, even when they expend great effort on the task (Margolis \& McCabe, 2004). This is problematic in that research has demonstrated that learners who do not have a high self-efficacy for a specific task tend not to be motivated to engage cognitively in a manner that is sufficient to meet the task demands (Winne, 2010). The ultimate result of this lack of motivation and engagement is academic achievement that falls below the task-specific expectations. As Margolis and McCabe (2004) suggested, the key to reversing this trend is for stakeholders to strengthen learners' self-efficacy for a task before actually engaging in the task, an instructional approach described below.

Promoting task understanding and self-efficacy in vulnerable readers is challenging. Margolis and McCabe (2004) pointed out that to establish higher self-efficacy learners must experience many successes with similar tasks. The success experienced with previous tasks becomes part of an internal feedback loop that informs learners' self-efficacy for the next task (Winne, 2010). This means that educators may be working with struggling readers who come to reading tasks without the necessary pre-requisite skills and processes necessary to engage effectively in self-regulatory learning. It then becomes the role of educators to transform the selfefficacy of struggling readers from one of poor self-efficacy, to one of perceived competency and motivation to engage. Educators can do this is by discussing the demands of the task itself and the time required of the task, discussing and practicing the strategies and tactics required to complete the task, and reviewing the criteria used to evaluate performance. By priming learners' understanding of these factors, they will develop a better understanding of expectations, a higher self-efficacy, and feel more motivated to engage (Winne, 2010).

In the context of the reading hierarchy proposed in this article, when teaching letter sounds, for example, it may be effective to discuss with readers that although there are a large number of letter sounds within the entire repertoire of the alphabet, the specific task is to master a small set of letter sounds. By enabling a vulnerable reader to understand that their task is to master five sounds per week for instance, the learner will understand that his or her task is manageable and achievable. Although this sounds like a simple educational tactic, without such a discussion, learners may come to a task with the understanding that their role is to learn 26 or more letter sounds - a daunting task for a young, vulnerable reader. By altering this understanding, children will be more willing to engage. In addition, task understanding as well as perceived self-efficacy may be increased by having vulnerable readers set task-specific goals.

\section{Goal Setting}

The role of goal setting in learning and achievement is particularly important in the selfregulatory learning process (Boekaerts \& Niemivirta, 2000; Paris \& Paris, 2010; Pintrich, 2000). 
Goal setting refers to planning particular outcomes of learning or performances. Goal setting and attainment enhances motivation, performance during the task, and perceived self-efficacy (Bandura, 1997; Schunk, 2002). However, goal setting is often not a natural process that learners will engage in without instruction in how to set goals effectively. It is important for vulnerable readers to engage in an effective goal setting process where they set and work toward attainable reading goals (Schunk, 2002). There are several factors essential for effective goal setting to occur. Research suggests that goals should be specific, proximal, and moderate in difficulty (Bandura, 1997; Locke \& Latham, 1990; Schunk, 2002). More specifically, a goal must have a clear standard that suggests the amount of effort required for success, be short-term and attainable within the given period, and not too easy or difficult to achieve.

It is important for struggling readers to set goals that have clear standards, define the task, and construct plans for attending to it (Winne, 2010). For example, within the context of the proposed reading hierarchy, when learning new sight words an effective goal might be to learn five new sight words within the instructional period. An important feature of this goal is specificity, or the specific learning of five new words. An ineffective goal would not include the specifics of five new sight words, but instead might be "trying harder to learn sight words." Creating specific goals allows the learner to focus on what needs to be done to complete the task (Locke \& Latham, 1990, 2002). Furthermore, it allows learners to monitor their progress in the process of attaining their goal. Research suggests that goals that include specific performance standards are more likely to activate self-evaluations and improve self-regulation than general standards such as "do my best" (Locke \& Latham, 1990, 2002; Pintrich, 2000). Specific goals that identify the amount of effort required for successful goal attainment not only improve performance but also enhance self-efficacy (Schunk, 2002).

Also, effective goals are short-term and attainable (Kozlowski \& Bell, 2006; Schunk, 1990). This is particularly important for children who struggle with reading. Children with reading difficulties often lack the motivation and self-efficacy to engage in tasks where they have been unsuccessful in the past. One way to change this ineffective cycle is to set goals where learners can immediately and frequently monitor their progress in achieving their goal. Without instructing children to create short-term and attainable goals for instance, they might attempt to learn 15 new sight words in one specific lesson. To help learners set more effective goals, educators may negotiate the goal to something short-term; for example, they may assist learners in breaking their goal into sub-goals of five words per lesson resulting in 15 new sight words by the end of the week. In this way, a child can achieve three short-term goals rather than achieving one broader goal at the end of the week. Such experiences of success result in higher motivation as they are attained more quickly than long-term goals, but also increase self-efficacy because they allow for frequent monitoring and evaluation of successful progress (Kozlowski \& Bell, 2006; Schunk, 1990; Pintrich, 2000).

Finally, goals should be moderately difficult to achieve (Locke \& Latham, 2002; Schunk, 1990). It has been suggested that easy goals do not demonstrate to learners their own capabilities and difficult goals often result in decreased motivation to engage in the task (VanderStoep \& Pintrich, 2003). When goals are moderately difficult, they challenge learners to persist and undertake their goal (Kozlowski \& Bell, 2006). When working with struggling readers, educators should assist learners in creating goals that are the appropriate level. While research suggests self-set goals are often more effective as they promote a stronger level of commitment to achievement (VanderStoep \& Pintrich, 2003), children new to goal setting might benefit from 
explicit instruction on how to set a moderately difficult goal. Thus, educators and learners should negotiate the goal, so learners can commit to the goal and feel the success of achievement.

\section{Strategies and Tactics}

A persistent challenge for struggling readers is that they do not know what learning strategies to employ when engaging with literacy tasks (Vaughn, Gersten, \& Chard, 2000). Although typical learners may engage with literacy activities using strategies they have implicitly modeled from observing their teachers or peers, vulnerable readers may not have acquired such understanding (Winne, 2010). Rather, at-risk readers may require explicit systematic instruction about the learning strategies that are required to complete the literacy task successfully. In other words, students with learning challenges require educators to explain in a step-by-step fashion how to work through a reading assignment, model the appropriate strategies to use when engaging in the task, and provide a great deal of guided practice and feedback (Margolis \& McCabe, 2004). In essence, educators should scaffold struggling readers' learning as they work through a task.

One challenge struggling readers may face is not knowing whether the strategy they have employed is actually working (Vaughn et al., 2000). Because of previous successes, average readers may be able to make internal decisions about the efficacy of the strategies they have employed thus increasing the likelihood that the strategies they are using will result in successful outcomes. If these learners make an internal decision that the strategy they are using is not working effectively, they may alter their learning strategies or choose a different approach to the task. The ability to regulate at this level may be facilitated by the cognitive resources of the average learner (Winne, 2011). That is, typical learners have the abilities to make internal decisions while simultaneously carrying out the task. Unfortunately, this may not be possible for struggling readers for two reasons. First, struggling readers may not have the experience of using successful strategies and second, they may not have the cognitive capacity to carry out this type of on-line monitoring. More specifically, the cognitive resources of struggling readers may be fully dedicated to carrying out the reading assignment, leaving little cognitive energy for on-line regulating of strategies (Winne, 2011).

It is not within the scope of the current paper to review all of the specific cognitive strategies and tactics available to vulnerable readers. There are a number of well-documented strategies for acquiring reading-based skills. However, it is important to adhere to some foundational strategic principles when working through the hierarchy of reading skills presented in the previous section. Struggling readers require a number of opportunities for guided practice (Scheeler, Macluckie, \& Albright, 2010). For instance, when first learning a phonetic principle (e.g., the distinction between "th" and "sh"), children should be provided with direct instruction of the principle and extended opportunities for repetition and practice. This may occur by an educator explicitly modeling the difference in sound and print associations of the two phonics blends. The student would follow this instruction by simply repeating and demonstrating his or her understanding of the sound and print distinctions between the blends. This type of direct instruction can be complemented with simple instructional tools (e.g., flash cards). Following this, it may be useful to reinforce the knowledge resulting from direct instruction with the use of a phonics activity or game. This type of reinforcement will complement students' initial learning and will enable them to see their own success with the concept in an applied situation. There are a number of published activities that can be used in this capacity. In general, this type of instructional approach (i.e., direct instruction followed by a related activity or game) can be used with each reading construct described in the reading hierarchy presented in this paper. 
In addition to understanding how to implement effective instructional strategies, it is important to consider the notion of mastery. Often, children with processing problems, such as those with reading disabilities, appear to have learned a concept by demonstrating proficiency at the time of the task (Swanson, Kehler, \& Jerman, 2010). However, it is also often the case that these children do not retain this information or demonstrate the ability to transfer this information to another similar educational situation (Swanson et al., 2010). This inability to sustain the initial knowledge suggests students have not yet mastered the concept. Therefore, it becomes the role of educators to ensure that vulnerable readers always work toward learning mastery. That is, poor readers have the opportunity to over-learn a concept to the point that they can maintain an understanding of the concept in a variety of different settings and educational situations.

\section{Monitoring and Feedback}

An important process within SRL is self-monitoring and feedback (Butler \& Winne, 1995; Winne \& Hadwin, 1998). Monitoring and providing oneself with feedback either during the task and/or after its completion allows learners to reinterpret how they are engaging with this task and how the resulting outcomes of the task may inform their subsequent engagement with similar endeavors. Following this, the notion of feedback, both internal and external is an important aspect of the self-regulatory learning process.

Effective learners often engage in a self-oriented feedback loop whereby they evaluate the efficacy of their learning strategies and make real-time decisions about whether the learning strategies they have employed will lead them to reach the goals that they have set (Zimmerman, 1989). If the result of this on-line monitoring produces an evaluation that signals to the learner that they are on-track to meet their goals, their use of current strategies and tactics will remain intact. However, if the result of learners' on-line monitoring signals a failure of strategies, they may adjust their engagement by establishing new goals or adapting existing ones; they may reevaluate strategies and select more productive tactics. A similar monitoring process may also occur at the completion of the instructional task. Effective learners often reflect on their task outcomes and couch their results in the context of the goals they set prior to engaging with the task (Zimmerman, 1989). Learners may attribute their success or failures in reaching their goals to internal factors such as effort or lack thereof, or external factors such as luck or deficiencies in the task or teacher. Effective learners tend to attribute both their successes and failure to internal factors (Zimmerman, 1989). This type of post-task monitoring and feedback underlies learner's motivation to engage with future tasks that are similar in nature. Therefore, it is important that educators support learners' effective monitoring of their learning both while learners are engaging in tasks and upon completion of the tasks. This may be of particular importance for vulnerable readers.

Before considering how to support struggling readers with the monitoring process, it is important to understand why vulnerable readers may not engage in this process to the same extent as their typically-achieving peers. Two related factors considered here include the notion that struggling readers may not naturally engage strategically with their own learning and related to this, learners may lack the cognitive resources available for such strategic engagement (Margolis $\&$ McCabe 2004). Both factors may be addressed by providing vulnerable readers with external sourced monitoring and feedback. In other words, educators should scaffold instruction to demonstrate how to monitor one's own learning (Butler \& Winne, 1995).

Assuming that vulnerable readers are not naturally engaging in real-time monitoring, it becomes the role of educators to teach struggling readers how to monitor their own learning 
effectively during and after a reading task. One approach to enable on-line monitoring is to relate students' learning to the goals that they set prior to engaging in the task. For instance, it may be effective to have students chart or graph their progress when learning sight words. Remembering that appropriate goals should be proximal and attainable, in tandem with their teacher, students may set a weekly goal of learning five new sight words over the course of three instructional sessions. After the first session, students may chart their progress (i.e., learned three new sight words during session 1) on an external graph, journal, or wordbook. Charting this progress (three new words) will enable learners to evaluate whether continuing this strategic course will lead to the weekly goal of five new words. In this particular case, educators may initiate a discussion with learners that indeed, learning three new words in the first session is in-line with the trajectory of the weekly goal and that the learner should continue this course of learning. This type of scaffolding around the internal monitoring process can be applied to any of the skills associated with the hierarchical reading acquisition process. For example, struggling readers can set goals and monitor their own progress with phonics principles, phoneme blends, fluency rate measured by words correct per minute, or comprehension questions. The intent here is that struggling readers will begin to internalize this monitoring process and eventually will not require the external prompts of graphs or charts. It is also expected that this process will enable struggling readers to see that they are capable of engaging with challenging literacy tasks in such a way that will result in the attainment of their goals-leading to a higher self-efficacy and in turn, increased motivation to engage in reading tasks.

\section{Conclusion}

The purpose of this article was to consider how a model of SRL might complement the reading acquisition process of vulnerable readers. Reading acquisition was conceptualized as a loose hierarchy where lower-order emergent literacy skills act as a foundation for higher-order skills such as sentence reading and comprehension. It was assumed that many vulnerable readers struggle with the emergent literacy skills necessary for effective word-level reading. It was also assumed that many vulnerable readers are susceptible to the Matthew Effect where their reading difficulties are compounded by motivational challenges. We hypothesized that by addressing contextual factors in addition to specific reading-based skills, vulnerable readers would be more willing to engage in challenging reading tasks. Specifically, the article described how educators may engage struggling readers in four processes proposed by Winne and Hadwin (1998) that support the development of self-regulation: (a) task understanding and perceived self-efficacy, (b) goal setting, (c) the development of strategies and tactics, and (d) monitoring and feedback.

The process of bridging a model of reading acquisition, remediation, and SRL holds important implications. First, research suggests that struggling readers often lack the self-efficacy to engage in reading acquisition. Following this, it is reasonable to expect that struggling readers are generally less motivated to engage in reading tasks. This is problematic in that achievement levels of vulnerable readers are often viewed in comparison to typically-achieving or even advanced learners - most of whom are engaging effectively with reading tasks. The differences in "willingness to engage" can create long-term gaps in achievement that are difficult to overcome. However, by improving struggling readers' self-efficacy, they may be more likely to engage in reading, and thus, progress successfully through the reading acquisition process. A second implication is based on the data indicating that the gap between grade-level and struggling readers grows exponentially throughout elementary school years (Stanovich, 1986). By engaging vulnerable readers' self-regulatory learning processes, they will be more likely to engage in 
independent learning and reading, thus decreasing the gap between grade-level and struggling readers' academic achievement. Finally, by facilitating the development of SRL, children can employ these skills in all areas of their education.

\section{References}

Adams, M. J. (1990). Beginning to read: Thinking and learning about print. Cambridge, MA: The MIT Press. Adams, M. J., Foorman, B. R., Lundberg, I., \& Beeler, T. (1998). Phonemic awareness in young children: A classroom curriculum. Baltimore, MD: Paul H. Brookes Publishing.

Ainley, M., \& Patrick, L. (2006). Measuring self-regulated learning processes through tracking patterns of student interaction with achievement activities. Educational Psychology Review, 18, 267-286. doi:10.1007 /s10648-006-9018-z

Azevedo, R. (2009). Theoretical, conceptual, methodological, and instructional issues in research on metacognition, and self-regulated learning: A discussion. Metacognition Learning, 4, 87-95. doi:10.1007 /s11409-009-9035-7

Azevedo, R., \& Witherspoon, A. M. (2009). Self-regulated use of hypermedia. In A. Graesser, J. Dunlosky, \& D. Hacker (Eds.), Handbook of metacognition in education (pp. 319-339). Mahwah, NJ: Lawrence Erlbaum.

Bandura, A. (1997). Self-efficacy: The exercise of control. New York, NY: Freeman.

Beech, J. R. (2005). Ehri's model of phases of learning to read: A brief critique. Journal of Research in Reading, 28, 50-58. doi:10.1111/j.1467-9817.2005.00252.x

Boekaerts, M., \& Niemivirta, M. (2000). Self-regulated learning: Finding a balance between learning goals and ego-protective goals. In M. Boekaerts, P. R. Pintrich, \& M. Zeidner (Eds.), Handbook of self-regulation (pp.13-39). San Diego, CA: Academic Press.

Bowers, P. G., \& Swanson, L. B. (1991). Naming speed deficits in reading disability: Multiple measures of a singular process. Journal of Experimental Child Psychology, 51, 195-219. doi:10.1016/00220965(91)90032-N

Butler, D. L. (1998). The strategic content learning approach to promoting self-regulated learning: A report of three studies. The Journal of Educational Psychology, 90, 682-697. doi:10.1037/0022-0663.90.4.682

Butler, D. L., \& Winne, P. H. (1995). Feedback and self-regulated learning: A theoretical synthesis. Review of Educational Research, 65, 245-281. doi:10.3102/00346543065003245

Caravolas, M., Hulme, C., \& Snowling, M. J. (2001). The foundations of spelling ability: Evidence from a 3year longitudinal study. Journal of Memory and Language, 45, 751-774. doi:10.1006/jmla.2000.2785

Cartwright, K. B. (Ed.). (2008). Literacy processes: Cognitive flexibility in learning and teaching. New York, NY: Guilford Press.

Case, L. P., Speece, D. L., \& Molloy, D. E. (2003). The validity of a response-to-instruction paradigm to identify reading disabilities: A longitudinal analysis of individual differences and contextual factors. School Psychology Review, 32, 557-582. Retrieved from http://education.illinoisstate.edu/downloads/casei /RtIvalidity.pdf

Castles, A., \& Coltheart, M. (2004). Is there a causal link from phonological awareness to success in learning to read? Cognition, 91, 77-111. doi:10.1016/S0010-0277(03)00164-1

Catts, H. W., Fey, M. E., Zhang, X., \& Tomblin, J. B. (2001). Estimating the risk of future reading difficulties in kindergarten children: A research-based model and its clinical implementation. Language, Speech, and Hearing Services in Schools, 32, 38-50. doi:10.1044/0161-1461(2001/004)

Corno, L. (1993). The best laid plans: Modern conceptions of volition and educational research. Educational Researcher, 22(2), 14-22. doi:10.3102/0013189X022002014

Cornwall, A. (1992). The relationship of phonological awareness, rapid naming and verbal memory to severe reading and spelling disability. Journal of Learning Disabilities, 25, 532-538. doi:10.1177 /002221949202500808

Crosnoe, R., Leventhal, T., Wirth, R. J., Pierce, K. M., \& Pianta, R. C. (2010). Family socioeconomic status and consistent environmental stimulation in early childhood. Child Development, 81, 972-987. doi:10 $.1111 /$ j.1467-8624.2010.01446.x

Ehri, L. C. (1992). Reconceptualizing the development of sight word reading and its relationship to recoding. 
In P. Gough, L. Ehri, \& R. Treiman (Eds.), Reading acquisition (pp. 107-143). Hillsdale, NJ: Lawrence Erlbaum.

Ehri, L. C. (2005). Learning to read words: Theories, findings, and issues. Scientific Studies of Reading, 9, 167-188. doi:10.1207/s1532799xssr0902_4

Fielding, L., Kerr, N., \& Rosier, P. (2007). Annual growth for all students, catch-up growth for those who are behind. Kennewick, WA: The New Foundation Press.

Fleming, S. (2006). The importance of sight words. All info about reading. Retrieved from http://www.allinfoaboutreading.com/the-importance-of-sight-words/

Foulin, J. N. (2005). Why is letter-name knowledge such a good predictor of learning to read? Reading and Writing, 18, 129-155. doi:10.1007/s11145-004-5892-2

Frith, U. (1985). Beneath the surface of developmental dyslexia. In K. E. Patterson, L. E. Marshall, \& M. Coltheart (Eds.). Surface dyslexia. Hillsdale, NJ: Lawrence Erlbaum.

Fuchs, L. S., Fuchs, D., Hosp, M. K., \& Jenkins, J. R. (2001). Oral reading fluency as an indicator of reading competence: A theoretical, empirical, and historical analysis. Scientific Studies of Reading, 5, 239-256. doi:10.1207/S1532799XSSR0503_3

Graham, A., McNamara, J. K., \& Van Lankveld, J. (2011). Sustainability of a family literacy program for vulnerable learners: A follow-up study of an exploratory study of a summer literacy program for kindergarten children at-risk for reading difficulties. Exceptionality Education International, 21, 15-27. Retrieved from http://ejournals.library.ualberta.ca/index.php/eei/index

Hecht, S. A., Burgess, S. R., Torgesen, J. K., Wagner, R. K., \& Rashotte, C. A. (2000). Explaining social class differences in growth of reading skills from beginning kindergarten through fourth grade: The role of phonological awareness, rate of access, and print knowledge. Reading and Writing: An Interdisciplinary Journal, 12, 99-127. doi:10.1023/A:1008033824385

Justice, L. M., \& Ezell, H. K. (2001). Word and print awareness in 4-year-old children. Child Language Teaching and Therapy, 17, 207-225. doi:10.1177/026565900101700303

Kozlowski, S. W., \& Bell, B. S. (2006). Disentangling achievement orientation and goal setting: Effects on self-regulatory processes. Journal of Applied Psychology, 91, 900-916. doi:10.1037/0021-9010.91.4 .900

Landerl, K., Frith, U., \& Wimmer, H. (1996). Intrusion of orthographic knowledge on phoneme awareness: Strong in normal readers, weak in dyslexic readers. Applied Psycholinguistics, 17, 1-14. doi:10.1017 /S0142716400009437

Locke, E. A., \& Latham, G. P. (1990). A theory of goal setting and task performance. Englewood Cliffs, NJ: Prentice Hall.

Locke, E. A., \& Latham, G. P. (2002). Building a practically useful theory of goal setting and task motivation: A 35-year odyssey. American Psychologist, 57, 705-717. doi:10.1037/0003-066X.57.9.705

Lodewyk, K., Winne, P. H., \& Jamieson-Noel, D. L. (2009). Implications of task structure on self-regulated learning and achievement. Educational Psychology, 29, 1-25. doi:10.1080/01443410802447023

Lyon, G. R., Fletcher, J. M., Shaywitz, S. E., Shaywitz, B. A., Torgesen, J. K., Wood, F. B.,...Olson, R. (2001). Rethinking learning disabilities. In C. E. Finn, Jr., R. A. J. Rotherham, \& C. R. Hokanson, Jr. (Eds.), Rethinking special education for a new century (pp. 259-287). Washington, DC: Thomas B. Fordham Foundation and Progressive Policy Institute.

Margolis, H., \& McCabe, P. (2004). Self-efficacy: A key to improving the motivation of struggling learners. The Clearing House, 77(6), 241-249. Retrieved from http://www.tandfonline.com/toc/vtch20/current\# .UsntxqWTMlI

McCardle, P., Scarborough, H. S., Catts, H. W. (2001). Predicting, explaining, and preventing children's reading difficulties. Learning Disabilities Research \& Practice, 16, 230-239. doi:10.1111/0938-8982.00023

McNamara, J. K., Scissions, M., \& Gutknecth, N. (2011). A longitudinal study of kindergarten children at-risk for reading disabilities: The poor really are getting poorer. Journal of Learning Disabilities, 44, 421430. doi: $10.1177 / 0022219411410040$

Morris, R. D., Lovett, M. W., Wolf, M., Sevcik, R. A., Steinbach, K. A., Frijters, J. C., \& Shapiro, M. B. (2012). Multiple-component remediation for developmental reading disabilities: IQ, socioeconomic status, and race as factors in remedial outcome. Journal of Learning Disabilities, 45, 99-127. doi:10 $.1177 / 0022219409355472$ 
National Reading Panel. (2000). Report of the national reading panel: Teaching students to read: An evidencebased assessment of the scientific research literature on reading and its implications for reading instruction: Reports of the subgroups. Bethesda, MD: National Institute of Child Health and Human Development, National Institutes of Health.

O'Connor, R. E., Notari-Syverson, A., \& Vadasy, P. F. (1996). Ladders to literacy: The effects of teacher-led phonological activities for kindergarten children with and without disabilities. Exceptional Children, 63, 117-130. Retrieved from http://journals.cec.sped.org/ec/

Paris, S. G., \& Paris, A. H. (2010). Classroom applications of research on self-regulated learning. Educational Psychologist, 36, 89-101. doi:10.1207/S15326985EP3602_4

Pennington, B. F., \& Lefly, D. L. (2001). Early reading development in children at-risk for dyslexia. Child Development, 72, 816-833. doi:10.1111/1467-8624.00317

Perfetti, C. A. (1992). The representation problem in reading acquisition. In P. B. Gough, L. C. Ehri, \& R. Treiman (Eds.), Reading acquisition (pp. 307-332). Hillsdale, NJ: Lawrence Erlbaum.

Phillips, B. M., Clancy-Menchetti, J., \& Lonigan, C. J. (2008). Successful phonological awareness instruction with preschool children: Lessons from the classroom. Topics in Early Childhood Special Education, 28, 3-17. doi:10.1177/0271121407313813

Pintrich, P. (2000). The role of goal orientation in self-regulated learning. In M. Boekaerts, P. Pintrich, \& M. Zeidner (Eds.), Handbook of self-regulation (pp. 451-502). San Diego, CA: Academic Press.

Scarborough, H. (1998). Predicting the future achievement of second graders with reading disabilities: Contributions of phonemic awareness, verbal memory, rapid naming, and IQ. Annals of Dyslexia, 48, 115136. doi:10.1007/s11881-998-0006-5

Scheeler, M. C., Macluckie, M., \& Albright, K. (2010). Effects of immediate feedback delivered by peer tutors on the oral presentation skills of adolescents with learning disabilities. Remedial and Special Education, 31,77-86. doi:10.1177/0741932508327458

Schunk, D. H. (1990). Goal setting and self-efficacy during self-regulated learning. Educational Psychologist, 25, 71-86. doi:10.1207/s15326985ep2501_6

Schunk, D. H. (2002). Self-regulation through goal setting. ERIC Digest, 1-4. Retrieved from http://www .schoolbehavior.com/Files/Schunk.pdf

Seymour, P. H. K., \& Elder, L. (1986). Beginning reading without phonology. Cognitive Neuropsychology, 3, 1-37. doi:10.1080/02643298608252668

Snow, C. E., Burns, M. S., \& Griffin, P. (1998). Preventing reading difficulties in young children. Washington, DC: National Academy Press.

Spear-Swerling, L., \& Sternberg, R. J. (Eds.). (1996). Off track: When poor readers become learning disabled. Boulder, CO: Westview Press.

Stanovich, K. E. (1986). Matthew effects in reading: Some consequences of individual differences in the acquisition of literacy. Reading Research Quarterly, 21, 360-407. Retrieved from http://www.jstor.org /stable/747612

Stuart, M. (1995). Predictive and qualitative assessment of five- and six-year old children's reading: A longitudinal study. British Journal of Educational Psychology, 65, 287-296. doi:10.1111/j.2044-8279 .1995.tb01150.x

Stuart, M., \& Coltheart, M. (1988). Does reading develop in a series of stages? Cognition, 30, 139-181. doi:10 $.1016 / 0010-0277(88) 90038-8$

Stuart, M., Stainthorp, R., \& Snowling, M. (2008). Literacy as a complex activity: Deconstructing the simple view of reading. Literacy, 42, 59-66. doi:10.1111/j.1741-4369.2008.00490.x

Swanson, H. L., Kehler, P., \& Jerman, O. (2010). Working memory, strategy knowledge, and strategy instruction in children with reading disabilities. Journal of Learning Disabilities, 43, 24-47. doi:10.1177 /0022219409338743

Taboada, A., Tonks, S. M., Wigfield, A., \& Guthrie, J. T. (2009). Effects of motivational and cognitive variables on reading comprehension. Reading and Writing, 22, 85-106. doi:10.1007/s11145-008-9133-y

Teale, W. H., \& Sulzby, E. (Eds.). (1986). Emergent literacy: Reading and writing. Westport, CT: Ablex Publishing.

Torgesen, J. K., Wagner, R. K., Rashotte, C. A., Burgess, S. R., \& Hecht, S. A. (1997). Contributions of phonological awareness and rapid autonomic naming ability to the growth of word-reading skills in second- 
to fifth-grade children. Scientific Study of Reading, 2, 161-185. doi:10.1207/s1532799xssr0102_4

Treiman, R., \& Kessler, B. (2004). The case of case: Children's knowledge and use of upper- and lowercase letters. Applied Psycholinguistics, 25, 413-428. doi:10.1017/S0142716404001195

VanderStoep, S. W., \& Pintrich, P. R. (2003). Learning to learn: The skill and will of college success. Upper Saddle River, NJ: Prentice Hall.

Vaughn, S., Gersten, R., \& Chard, D. J. (2000). The underlying message in LD intervention research: Findings from research syntheses. Exceptional Children, 67, 99-114. Retrieved from http://journals.cec.sped .org/ec/

Venkatesh, V., \& Shaikh, K. (2011). Uncovering relationships between task understanding and monitoring proficiencies in postsecondary learners: Comparing work task and learner as statistical units of analyses. Education Research International, 2011, 1-11. doi:10.1155/2011/735643

Verhoeven, L., \& Perfetti, C. A. (2011). Morphological processing in reading acquisition: A cross-linguistic perspective. Applied Psycholinguistics, 32, 457-466. doi:10.1017/S0142716411000154

Wagner, R. K., Torgesen, J. K., \& Rashotte, C. A. (1994). Development of reading-related phonological processing abilities: New evidence of bidirectional causality from a latent variable longitudinal study. Developmental Psychology, 30, 73-87. doi:10.1037/0012-1649.30.1.73

Winne, P. H. (2010). Improving measurements of self-regulated learning. Educational Psychologist, 45, 267276. doi:10.1080/00461520.2010.517150

Winne, P. H. (2011). A cognitive and metacognitive analysis of self-regulated learning. In B. J. Zimmerman \& D. H. Schunk (Eds.), Handbook of self-regulation of learning and performance (pp. 15-32). New York, NY: Routledge.

Winne, P. H., \& Hadwin, A. F. (1998). Studying as self-regulated learning. In D. J. Hacker, J. Dunlosky, \& A. C. Graesser (Eds.), Metacognition in educational theory and practice (pp. 277-304). Mahwah, NJ: Lawrence Erlbaum.

Winne, P. H., \& Hadwin, A. F. (2008). The weave of motivation and self-regulated learning. In D. H. Schunk \& B. J. Zimmerman (Eds.), Motivation and self-regulated learning: Theory, research, and applications (pp. 297-314). Mahwah, NJ: Lawrence Erlbaum.

Zimmerman, B. J. (1989). Models of self-regulated learning and academic achievement. In B. J. Zimmerman \& D. H. Schunk (Eds.), Self-regulated learning and academic achievement: Theory, research, and practice (pp. 1-25). New York, NY: Springer-Verlag.

Zimmerman, B. J. (2008). Investigating self-regulation and motivation: Historical background, methodological developments, and future prospects. American Educational Research Journal, 45, 166-183. doi:10.3102 /0002831207312909

Zimmerman, B. J., \& Schunk, D. H. (Eds.). (1989). Self-regulated learning and academic achievement: Theory, research, and practice. New York, NY: Springer-Verlag.

\section{Authors' Note}

Correspondence concerning this article should be addressed to Sierra Holtzheuser, Brock University, Department of Child and Youth Studies, St. Catharines, ON, Canada, L2S 3A1.

Email: sierra.holtzheuser@brocku.ca 